Abstracted/indexed in Academic Search Complete, Agroforestry Abstracts, Asia Journals Online, Bangladesh Journals Online, Biological Abstracts, BIOSIS Previews, CAB Abstracts, Current Abstracts, Directory of Open Access Journals, EMBASE/Excerpta Medica, Google Scholar, HINARI (WHO), International Pharmaceutical Abstracts, Open J-gate, Science Citation Index Expanded, SCOPUS and Social Sciences Citation Index

ISSN: $1991-0088$

\title{
Combination of perindopril/indapamide in secondary prevention of stroke and other vascular events: A combined analysis of ADVANCE, PROGRESS and HYVET trials
}

\author{
Sougat S. Sarkar
}

Glenmark Pharmaceuticals Ltd, Mumbai. India

\begin{tabular}{|c|c|}
\hline \multicolumn{2}{|l|}{ Article Info } \\
\hline Received: & 5 July 2011 \\
\hline Accepted: & 6 July 2011 \\
\hline Available Online: & 8 July 2011 \\
\hline \multicolumn{2}{|c|}{ DOI: 10.3329/bjp.v6i1.7920 } \\
\hline \multicolumn{2}{|l|}{ Cite this article: } \\
\hline \multicolumn{2}{|c|}{$\begin{array}{l}\text { Sarkar SS. Combination of perin- } \\
\text { dopril/indapamide in secondary } \\
\text { prevention of stroke and other vascu- } \\
\text { lar events: A combined analysis of } \\
\text { ADVANCE, PROGRESS and HYVET } \\
\text { trials. Bangladesh J Pharmacol. 2011; } \\
\text { 6: } 25-33 \text {. }\end{array}$} \\
\hline
\end{tabular}

\section{Abstract}

Perindopril/indapamide combination has been shown to reduce cardiovascular risk in different groups of patients. A total of 18,529 patients $(9,272$ receiving perindopril/indapamide and 9,257 receiving placebo) were included in this meta-analysis involving three large randomized clinical trials -ADVANCE, PROGRESS and HYVET. A non-significant reduction in fatal and non-fatal stroke was seen (odds ratio $0.73 ; 95 \%$ confidence interval 0.5 to $1.1 ; \mathrm{z}=1.5$ and $\mathrm{p}=0.13$ ). The fixed combination perindopril and indapamide was associated with a significant reduction of vascular death (odds ratio 0.79; $95 \%$ Confidence Interval 0.7 to $0.9 ; z=3.5$ and $p=0.0005$ ) and major cardiovascular events (odds ratio $0.72 ; 95 \%$ Confidence Interval 0.5 to $1.0 ; z=2.2$ and $\mathrm{p}=0.03$ ). However, effect on stroke needs further evaluation.

\section{Introduction}

Hypertension is one of major contributor to global mortality and is responsible for approximately 7.1 million deaths each year (Kearney et al., 2005). It increases the risk of heart attack, heart failure, stroke, and kidney disease (Chobanian et al., 2003; Stamler et al., 1993).

The primary aim of an effective antihypertensive treatment strategy is to lower elevated blood pressure to target levels and to achieve a maximum reduction in risk. Many clinical trials have shown that blood pressure reduction by a variety of strategies reduces the risk of stroke by approximately 35\%, congestive heart failure by $42 \%$ and coronary heart disease by $28 \%$ (ALLHAT, 2002; Gueyffier et al., 1996; Psaty et al., 1997 and SHEP, 1991).

Monotherapy has been the standard initial treatment approach in most patients with hypertension and combination therapy is initiated when stepwise increases in the dose of the single agent fail to achieve the required blood pressure reduction.
The rationale behind combination therapy, using two or more drugs with different and complementary mechanisms of action, is the potential to improve blood pressure control by the combined effects and, by allowing lower doses of the drugs, to reduce unwanted side-effects. Significant discrepancies exist on the question of which combinations of antihypertensive drugs should be employed. While JNC-7 recommends a diuretic to be included in a 2-drug combination strategy, the European guideline recommends various combinations both with and without a diuretic (Chobanain et al., 2003 and ESC/ESH, 2007). More specifically, the recently revised European (ESC/ESH) guidelines recommend the following options for 2-drug combinations: Diuretic plus either calcium channel blocker or renin-angiotensin system blocker (ACE inhibitor or angiotensin receptor blocker) or calcium channel blocker plus renin-angiotensin system blocker (Mancia et al., 2009). Also, the use of ACE-inhibitors is recommended in guidelines on the management of stable coronary artery disease, myocardial infarction, and heart failure (ESC, 2006; Wood et al., 1998; Lopez- 
Sendon et al., 2004).

Among all the ACE-inhibitors, perindopril has been extensively investigated in this regard and has been shown to improve endothelial function and neurohumoral balance, and inhibit remodelling of the coronary arteries (Bots et al., 2007; Rodriguez-Granillo et al., 2007 and Ceconi et al., 2007). The beneficial effects of combination of perindopril and Indapamide, a diuretic in reducing blood pressure have been demonstrated in many trials and meta-analysis. Perindopril/ indapamide provided additional antihypertensive efficacy when compared with each component used alone and major efficacy on systolic blood pressure, an important predictor of cardiovascular risk compared with current monotherapy. It also reduced pulse pressure, large-vessel arterial stiffness and microcirculatory alterations (Rodriguez-Granillo et al., 2007). Perindopril/indapamide also reduced target organ damage in patients at high cardiovascular risk (Gosse, 2006). Most of these studies were conducted in patient populations with vascular disease in a single vascular territory or with a metabolic disorder such as diabetes. Thus, a study that included patients of various age groups with a wider spectrum of vascular disease is needed. As there is paucity of literature which analyzes perindopril/indapamide combination for risk reduction, the present analysis is conducted.

\section{Materials and Methods}

\section{Identification, inclusion and exclusion}

Literature searches were performed using MEDLINE/ PubMed and CENTRAL (Cochrane Central Register of Controlled Trials) up to May 2011 with the following search terms: "Perindopril" and "Indapamide" or "Perindopril Indapamide" or "Perindopril Indapamide secondary prevention". These search terms resulted in 302 primary articles from the PubMed database which included 50 reviews. The resulting articles were then manually screened and duplicates removed. Articles were included if the trial is a) double blind randomized clinical trial, b) include any of the Secondary Prevention parameter- stroke, cardiovascular mortality, etc, c) had a follow-up for at least 1 year, and d) article in English language.

J-PADOC trial was excluded as it was an observational study. P.I.X.C.E.L, PREMIER and REASON study were also excluded as secondary prevention criteria was not met. Thus, three large clinical trials-ADVANCE(Action in Diabetes and Vascular Disease: Preterax and Diamicron Modified-Release Controlled Evaluation), HYVET (Hypertension in the Very Elderly Trial) and PROGRESS (Perindopril Protection Against Recurrent Stroke Study) were included for analysis (Figure 1).

\section{End points}

The endpoints of interest for the present analysis were prevention of fatal or non-fatal strokes, major cardiovascular event, vascular death, myocardial infarction and all cause mortality.

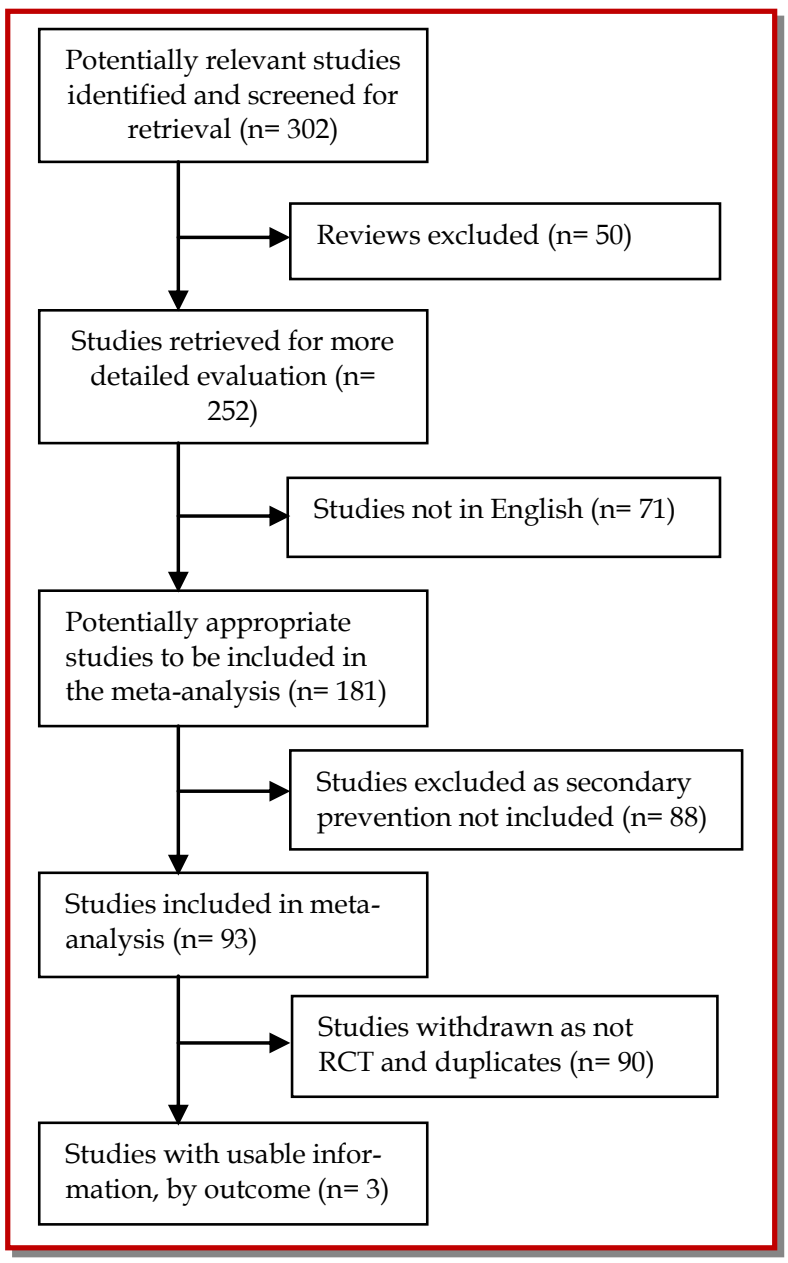

Figure 1: Flow-diagram of included studies

\section{Statistical analysis}

Trial data experiencing a clinical outcome and the total number of study participants for each arm were used to determine odds ratios for each study and were analyzed using Review Manager (RevMan) version 5.0. As all data were dichotomous, the Mantel-Haenszel method was used for all odds ratio. Statistical heterogeneity was determined by using $\chi^{2}$ test. A $p$ value of less than 0.10 indicates heterogeneity. A random effects model was used for all analyses. Ninetyfive percent confidence interval was used throughout and $\mathrm{P}$ values less than 0.05 was considered statistically significant. 


\section{Results}

The present study aims to analyze the effect of combination of perindopril and indapamide and hence included patients of various ages. Three large multicentric double-blind randomized placebo controlled trials- ADVANCE (ADVANCE, 2007), HYVET (HYVET, 2008) and PROGRESS (PROGRESS, 2001) were included for the present analysis.

A total of 18,529 patients $(9,272$ receiving combination of perindopril and indapamide and 9,257 receiving placebo) were included in this meta-analysis. $43.7 \%$ of the total patients were females (Table I). Patients receiving either combination of perindopril and indapamide or receiving double placebo in PROGRESS study were included in the present analysis. Data involving single drug or involving both single and combination drugs were not included for analysis. So in PROGRESS trial, data involving 3,544 out of a total of 6,105 patients were analyzed.

All the three studies reported stroke as a primary or secondary endpoint (Table II). The number of patients experiencing fatal or non-fatal stroke included in this analysis were 958 (5.2\% of total) of which 416 (4.5\% of combination) received combination of perindopril and indapamide and 542 (5.9\% of placebo) received placebo (Figure 2 and 3). A non-significant reduction in fatal
Table I

\begin{tabular}{|c|c|c|c|}
\hline \multicolumn{4}{|c|}{$\begin{array}{c}\text { Main features of the ADVANCE, PROGRESS } \\
\text { and HYVET trials }\end{array}$} \\
\hline Characteristics & $\begin{array}{c}\text { AD- } \\
\text { VANCE }\end{array}$ & $\begin{array}{c}\text { PRO- } \\
\text { GRESS* }\end{array}$ & HYVET \\
\hline $\begin{array}{l}\text { Number of sub- } \\
\text { jects }\end{array}$ & 11,140 & 3,544 & 3,845 \\
\hline $\begin{array}{l}\text { Mean age } \\
( \pm \text { SD) }\end{array}$ & $\begin{array}{l}66 \\
(6)\end{array}$ & $\begin{array}{l}63 \\
(9)\end{array}$ & 83.5 \\
\hline Number of fe- & 4,735 & 1,043 & 2,326 \\
\hline males (\%) & $(42.5)$ & $(29)$ & $(60.5)$ \\
\hline $\begin{array}{l}\text { History of stroke } \\
(\%)\end{array}$ & 13 & 71 & 7 \\
\hline $\begin{array}{l}\text { History of myo- } \\
\text { cardial infarction } \\
(\%)\end{array}$ & 12 & 7 & 3 \\
\hline $\begin{array}{l}\text { History of heart } \\
\text { disease }(\%)\end{array}$ & 39 & 18 & 12 \\
\hline $\begin{array}{l}\text { History of diabe- } \\
\text { tes }(\%)\end{array}$ & 100 & 12 & 7 \\
\hline $\begin{array}{l}\text { Current smoker } \\
(\%)\end{array}$ & 15 & 20 & 7 \\
\hline $\begin{array}{l}\text { Mean systolic } \\
\text { blood pressure in } \\
\mathrm{mm} \text { of } \mathrm{Hg}( \pm \mathrm{SD})\end{array}$ & $\begin{array}{l}145 \\
(21)\end{array}$ & $\begin{array}{l}149 \\
(19)\end{array}$ & $\begin{array}{r}173 \\
(8.5)\end{array}$ \\
\hline $\begin{array}{l}\text { Mean diastolic } \\
\text { blood pressure in } \\
\mathrm{mm} \text { of } \mathrm{Hg}( \pm \mathrm{SD})\end{array}$ & $\begin{array}{r}81 \\
(11)\end{array}$ & $\begin{array}{r}87 \\
(11)\end{array}$ & $\begin{array}{r}91 \\
(8.5)\end{array}$ \\
\hline
\end{tabular}

Table II

Baseline characteristics patients in the ADVANCE, PROGRESS and HYVET trials

\begin{tabular}{|c|c|c|c|}
\hline Features & ADVANCE & PROGRESS & HYVET \\
\hline \multicolumn{4}{|l|}{ Main inclusion criteria } \\
\hline Age at entry (year) & $>55$ & Not specified & $>80$ \\
\hline Type of patients (entry) & Diabetes mellitus & Stroke or TIA & \\
\hline \multicolumn{4}{|l|}{ Main exclusion criteria } \\
\hline Known congestive heart failure & No & No & $\begin{array}{l}\text { Yes requiring treat- } \\
\text { ment with antihyper- } \\
\text { tensive medication }\end{array}$ \\
\hline Stroke & - & Within 5 years & Within 6 months \\
\hline ACE-inhibitor and target daily dose & $\begin{array}{l}\text { Perindopril } 4 \mathrm{mg} / \\
\text { indapamide } 1.3 \mathrm{mg}\end{array}$ & $\begin{array}{l}\text { Perindopril } 4 \mathrm{mg} / \\
\text { indapamide } 2.5 \mathrm{mg} \text { (except } \\
\text { Japan } 2 \mathrm{mg} \text { ) }\end{array}$ & $\begin{array}{l}\text { Perindopril } 4 \mathrm{mg} / \\
\text { indapamide SR } 1.5 \mathrm{mg}\end{array}$ \\
\hline \multicolumn{4}{|l|}{ Main outcomes } \\
\hline Primary (composite) & $\begin{array}{l}\text { Major macro- or micro- } \\
\text { vascular events }\end{array}$ & Fatal or non-fatal stroke & Fatal or nonfatal stroke \\
\hline Secondary and others & $\begin{array}{l}\text { All-cause mortality, cardio- } \\
\text { vascular mortality, non- } \\
\text { fatal MI, fatal- and non-fatal } \\
\text { stroke, revascularization, } \\
\text { heart failure admissions, } \\
\text { new or worsening nephrop- } \\
\text { athy }\end{array}$ & $\begin{array}{l}\text { All-cause mortality, cardio- } \\
\text { vascular mortality, non-fatal } \\
\text { MI, fatal- and non-fatal } \\
\text { stroke, revascularization, } \\
\text { heart failure admissions }\end{array}$ & $\begin{array}{l}\text { death from any cause, } \\
\text { death from cardiovas- } \\
\text { cular causes, death } \\
\text { from cardiac causes, } \\
\text { and death from stroke }\end{array}$ \\
\hline Recruitment period & June 2001 to March 2003 & May 1995 to November 1997 & 2001 to 2007 \\
\hline Mean follow-up duration & 4.3 years & 3.9 years & 2.1 years \\
\hline
\end{tabular}




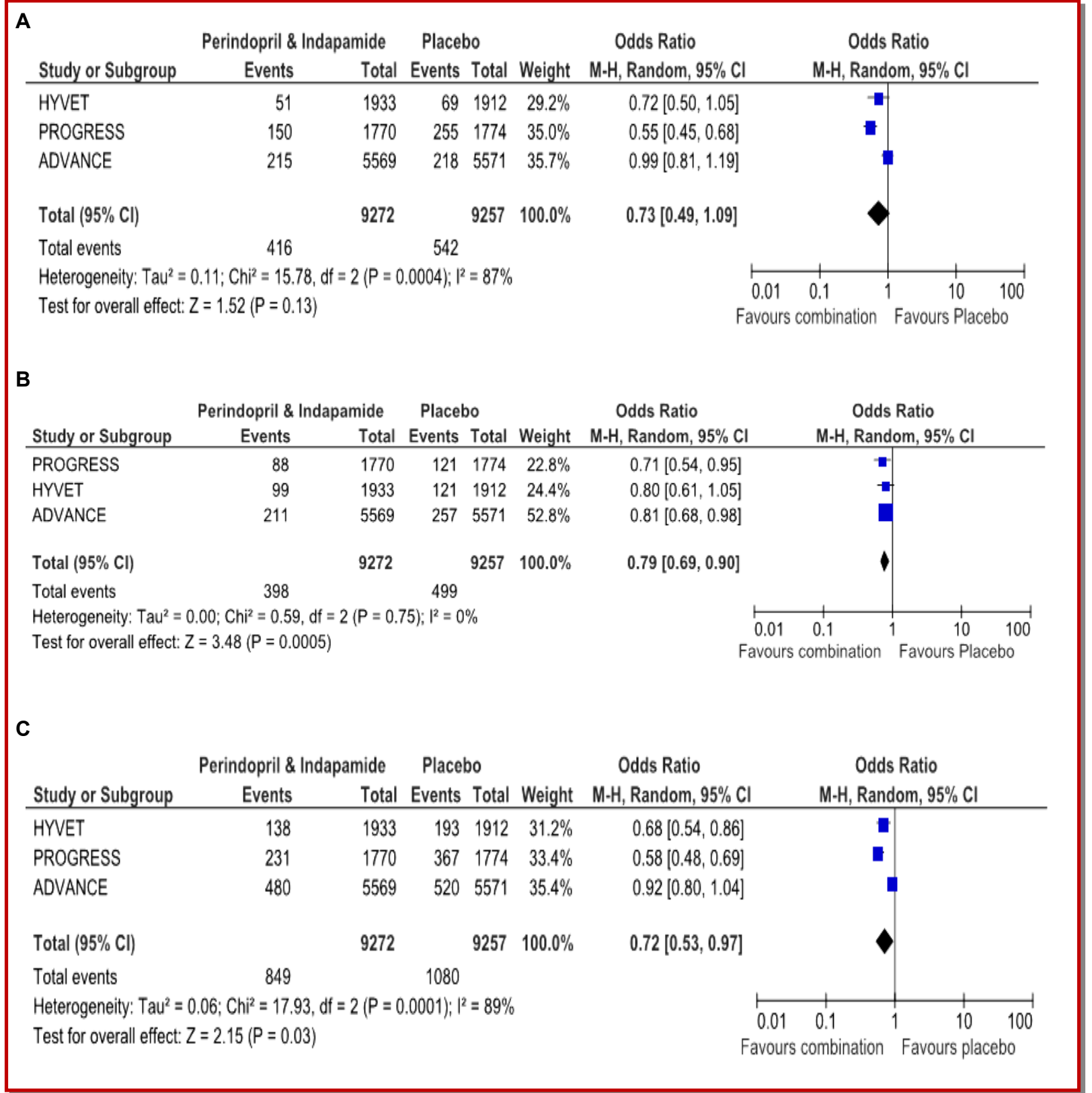

Figure 2: Forest plots of the effect of perindopril/Indapamide in patients with/without prior stroke or TIA on odds on (A) subsequent stroke (fatal and nonfatal); (B) vascular death; (C) major cardio-vascular events (combined stroke, MI, or vascular death). The weights represents relative weight given to study. The final column gives point estimates of Odds ratio and $95 \%$ confidence interval

and non-fatal stroke was seen (Odds ratio 0.7; 95\% Confidence Interval 0.5 to 1.1). This combination reduces the odds of fatal and non-fatal stroke by $27 \%$ of what they were in placebo group. However, a significant reduction in fatal and non-fatal stroke (Odds ratio 0.6 ; $95 \%$ Confidence Interval 0.5 to 0.8 ) is observed if HYVET and PROGRESS trials are only analyzed (Figure 4).
There were $4.3 \%$ vascular deaths in patients using combination as compared to $5.4 \%$ using placebo (Figure 2 and 3). This combination significantly decreased the vascular death (Odds ratio 0.8; 95\% Confidence Interval 0.7 to 0.9 ). Thus, this combination reduces the odds of vascular deaths by $21 \%$ of what they were in placebo group. However, more weight was given to ADVANCE. 


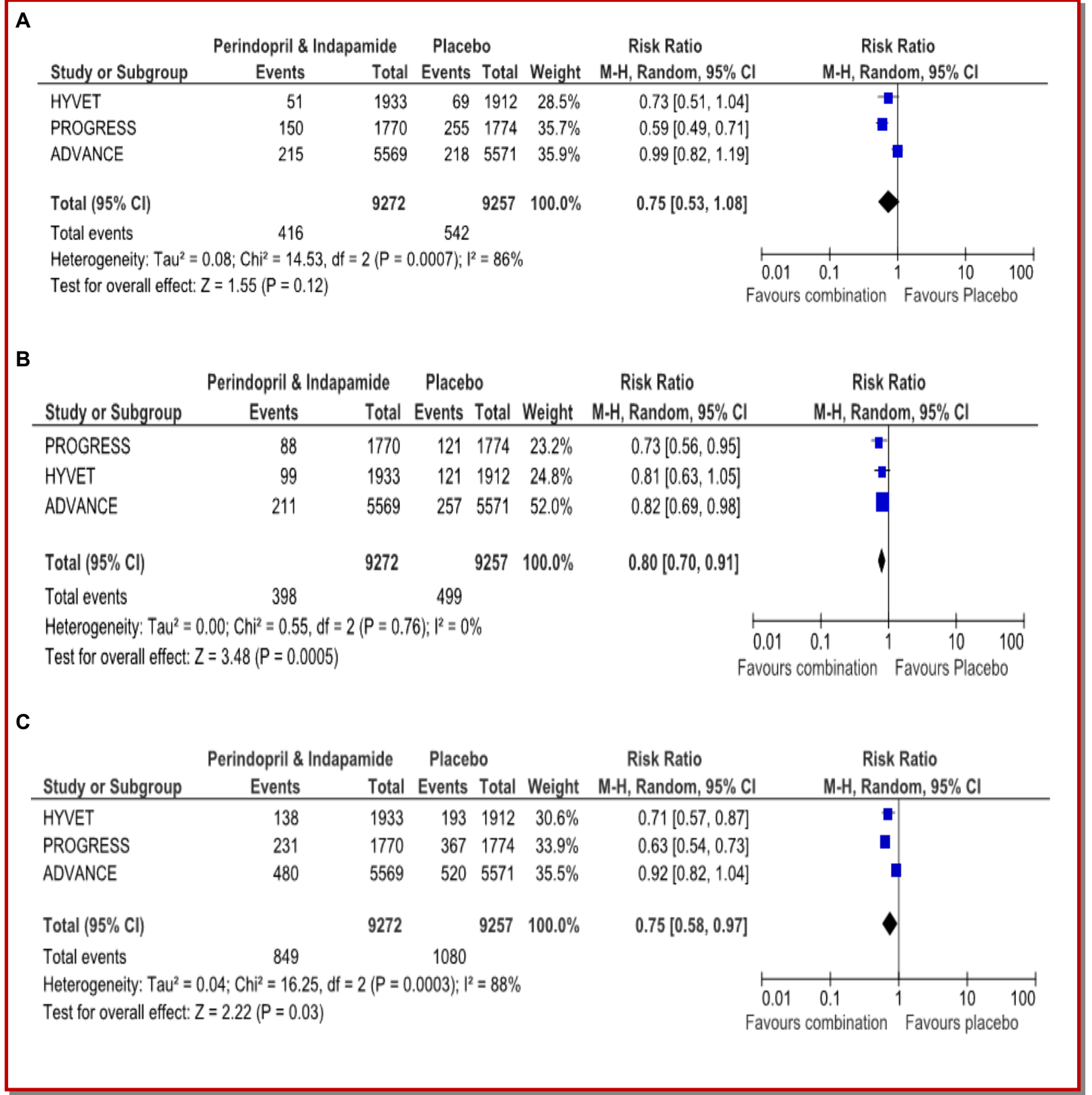

Figure 3: Forest plots of the effect of perindopril/Indapamide in patients with/without prior stroke or TIA on risk of (A) subsequent stroke (fatal and nonfatal); (B) vascular death; (C) major cardio-vascular events (combined stroke, MI, or vascular death). The weights represents relative weight given to study. The final column gives point estimates of risk ratio and $95 \%$ confidence interval

Major cardio-vascular events comprised of combined stroke, myocardial infarction, or vascular death. Significant reduction was also seen in major cardiovascular events (odds ratio $0.7 ; 95 \%$ confidence interval 0.5 to 1.0). This combination reduces the odds of major cardiovascular event by $28 \%$ of what they were in placebo group (Figure 2 and 3).

A considerable degree of heterogeneity was found in analysis of fatal or non-fatal stroke $\left(\mathrm{I}^{2}=87 \% ; \mathrm{p}=0.0004\right)$ and major cardio-vascular events $\left(I^{2}=89 \% ; \mathrm{p}=0.0001\right)$.
However, no heterogeneity was found in analysis of vascular deaths $\left(\mathrm{I}^{2}=0 \% ; \mathrm{p}=0.75\right)$ and fatal or non-fatal stroke excluding ADVANCE $\left(\mathrm{I}^{2}=36 \% ; \mathrm{p}=0.21\right)$.

Non-availability of data for myocardial infarction and all cause mortality for the combination in PROGRESS study lead to only analyze fatal or non-fatal strokes, major cardiovascular event and cardiovascular mortality. 


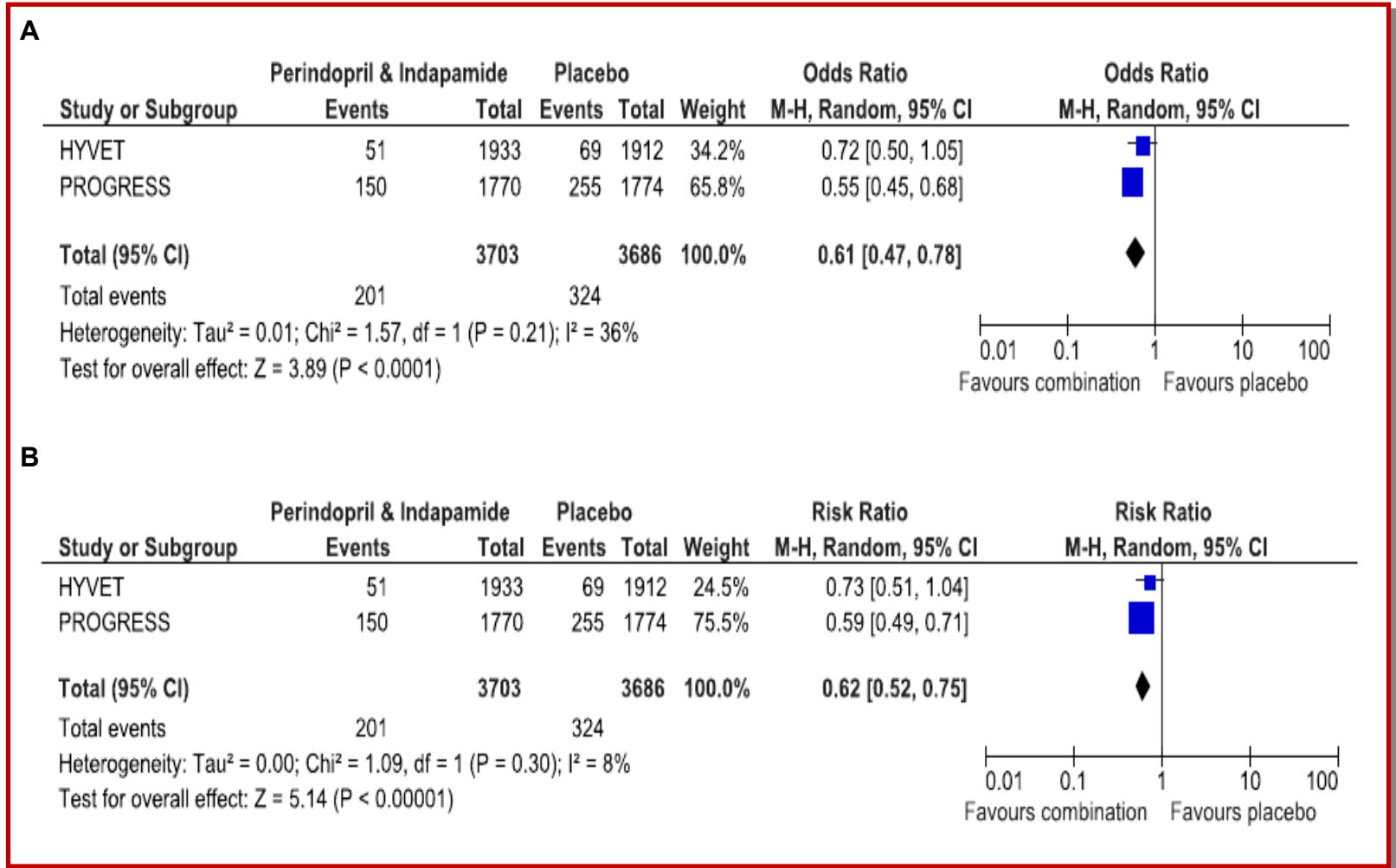

Figure 4: Forest plots of the effect of perindopril/Indapamide on (A) odds and (B) risk on subsequent stroke (fatal and nonfatal) excluding Advance. The weights represents relative weight given to study. The final column gives point estimates of Odds ratio and $95 \%$ confidence interval

\section{Discussion}

JNC 7 states that most patients with hypertension will require 2 or more antihypertensive medications to achieve goal blood pressure $(<140 / 90 \mathrm{~mm} \mathrm{Hg}$, or $<130 / 80 \mathrm{~mm} \mathrm{Hg}$ for patients with diabetes or chronic kidney disease); If blood pressure is more than 20/10 $\mathrm{mm} \mathrm{Hg}$ above goal blood pressure, consideration should be given to initiating therapy with 2 agents, 1 of which usually should be a thiazide-type diuretic (Chobanian et al., 2003). Indapamide is called a thiazide-like diuretic but structure lacks the thiazo-ring and its fixed dose combination with perindopril offers as an alternative to treat patients requiring these two class of drugs.

Two meta-analysis (Kang et al., 2004; Laurent, 2003) demonstrated fixed, low-dose perindopril/indapamide combination's favorable safety profile and effectiveness as first-line treatment for patients with mild to moderate essential hypertension. This combination also reduced the incidence of hypokalemia seen with indapamide alone (McClellan and Markham, 1999). Cardiovascular prevention with perindopril, in combination with indapamide, has been also shown in the elderly and patients with diabetes, cardio- and cerebrovascular diseases in large randomized clinical trials. A broad use of perindopril/indapamide for the long-term improvement of prognosis in hypertensive patients as well as in patients with diabetes was also supported (Mancia and Grassi, 2009). The low-dose perindopril/indapamide can be applied as first-line treatment by physicians who care for patients with elevated blood pressure or, more broadly, those with cardiovascular disease was also stated (De Leeuw, 2011).

So, the present analysis tested perindopril-indapamide combination in secondary prevention. Data from PROGRESS which involved single drug have been not taken into account in this analysis so as to analyze only the combination effect. Base on the result from this analysis, this combination did not significantly reduce fatal or non-fatal stroke but reduced vascular deaths and decreased major cardio-vascular events. However, perindopril/indapamide reduced the risk of fatal or non fatal stroke by $25 \%$ of what it was with placebo. Three trials (6,216 patients) studied a diuretic (Carter, 1970; Hypertension study, 1974; PATS, 1995); the largest of these, PATS (5,665 patients), reported that indapamide reduced stroke recurrence by $29 \%$. Similar results of indapamide in reducing stroke were also seen in meta-analysis (Liu et al., 2009; Brodszky et al., 2007). A meta-analysis of perindopril (Snyman and Wessels, 2009) demonstrated a highly significant reduction in event rate of stroke (OR 0.8/; 95\% CI: 0.7-0.9; $\mathrm{p}<$ 
0.0001). Individual large trial such as PROGRESS showed dual antihypertensive therapy (perindopril and indapamide) was superior to mono therapy (perindopril) in reducing stroke recurrence (relative risk reduction 43 vs $5 \%$ ) and HYVET observed $30 \%$ reduction in stroke. ADVANCE showed low stroke reduction and no treatment benefit with this combination. So, analysis excluding ADVANCE was done and combined analysis of HYVET and PROGRESS not only showed significant reduction in stoke event but also 38\% risk reduction with no heterogeneity. The author was unable to find published meta-analysis of stroke reduction with perindopril/indapamide combination for comparing the result of analysis.

Perindopril/indapamide significantly reduced the risk of vascular death by $20 \%$ and of major cardiovascular events by $25 \%$ of what it was with placebo in this analysis. Vascular death was also reduced significantly in individual trials such as HYVET 19\%, ADVANCE $18 \%$ and PROGRESS $27 \%$ relative risk reduction. A significant $11 \%$ reduction in mortality with perindopril alone in six outcome trials was found (Snyman and Wessels, 2009). Thus, by result of this meta-analysis, it can be said that perindopril/indapamide reduces more vascular death than perindopril alone. The same trend is also seen in reduction of major cardio-vascular event. Although no meta-analysis showing effect of perindopril/indapamide combination on major cardiovascular events were published till date, the result of this meta-analysis is as par with the result of Rashid et al. (2003) who found combination of ACE inhibitor and diuretic reduces major vascular events. The present analysis confirms the opinion (Ghiadoni, 2011) that combination therapy with indapamide or amlodipine with perindopril reduces cardiovascular events and mortality in hypertensive patients. A study (Brugts et al., 2009) also provided strong evidence for a consistent cardiovascular protection with an ACE-inhibitor treatment regimen (perindopril-indapamide) by improving survival and reducing the risk of major cardiovascular events across a broad spectrum of patients with vascular disease. Major cardiovascular events were reduced by $29 \%$ in HYVET, $36 \%$ in PROGRESS and low of $8 \%$ in ADVANCE of what it was with placebo. The pooled analysis of these trials in this analysis shows that the combination reduces the risk of major cardio-vascular events by 4 percentage points.

There is ample evidence that perindopril/indapamide has actions on the heart and blood vessels that may reduce cardiovascular disease. Apart from animal studies, clinical trials exploded action of both these drugs as well as combination. Comparing with atenolol, Ghiadoni et al. (2009) found improvement of endothelium-dependent vasodilation with treatment with perindopril/indapamide in comparison with atenolol. Also, improvement in endothelium-independent and sympathetic-associated vasodilation was also observed in the study. The study results suggested long-term therapy with a fixed-dose combination of perindopril/ indapamide affords vascular protection in hypertensive patients. Recent HYVET study (Bulpitt et al., 2011) also discussed greater benefits of the combination due to unknown properties of indapamide or perindopril. Debbabi et al. (2010) found that blood pressure controlled hypertensive patients had normalized capillary density and endothelial function with perindopril/indapamide whereas other antihypertensive treatments, excluding ACE inhibitors or diuretics, had less effect despite similar blood pressure control. Thus, the result of this analysis may reflect the class effect of ACE inhibitors in combination with diuretics. As the present analysis compared combination of active drug with placebo, randomized clinical trials and analysis of this drug combination with active competitor needs to be carried out.

\section{This work has several limitations}

Limitation 1: Trial-level data rather than individual patient data were assessed since the latter were not available. Analyses based on individual patient data are generally superior and also allow subgroup analyses to be performed.

Limitation 2: Assessment of the effect of lowering blood pressure in patients with different secondary outcomes could not be assessed as since all the trials included did not report these data separately.

Limitation 3: The baseline blood pressure varied among the trials included- in HYVET was approximate 173/91 $\mathrm{mm} \mathrm{Hg}$ whereas other two trials was approximate $147 / 84 \mathrm{~mm} \mathrm{Hg}$. This might have also affected the outcomes.

Limitation 4: Fatal or disabling stroke would have been more relevant in Patient's view. It was not possible to analyze fatal stroke due to non-availability of data.

Limitation 5: There was significant heterogeneity in this analysis. Such heterogeneity can be related to differences across trials in patient selection, concomitant medication, length of follow-up, etc. The result from indirect comparisons, are only exploratory, with a weak level of evidence and will not be possibly assessed even in a meta-analysis on individual patient data.

Limitation 6: The dose of Indapamide was different in each included trials- $1.3 \mathrm{mg}$ in ADVANCE, $2.5 \mathrm{mg}$ in PROGRESS (2 $\mathrm{mg}$ in Japan) and $1.5 \mathrm{mg}$ in HYVET. This might have affected the outcome as PROGRESS used double dose of indapamide as compared to ADVANCE

Limitation 7: As data involving reduction of heart failure, myocardial infarction (fatal or non-fatal), hospital admission, etc were not available from the included trial, the analysis of these secondary parameters could not be performed. 


\section{Conclusion}

Evaluation of three large randomized clinical trials, fixed-combination of perindopril and indapamide substantially reduced major cardiovascular event and vascular death. However, effect on stroke needs further evaluation.

\section{References}

ADVANCE Collaborative Group. Effects of a fixed combination of perindopril and indapamide on macrovascular and microvascular outcomes in patients with type 2 diabetes mellitus (the ADVANCE trial): A randomised controlled trial. Lancet 2007; 370: 829-40.

ALLHAT Officers and Coordinators for the ALLHAT Collaborative Research Group. Major outcomes in high-risk hypertensive patients randomized to angiotensin-converting enzyme inhibitor or calcium channel blocker vs diuretic: The Antihypertensive and Lipid-Lowering Treatment to Prevent Heart Attack Trial (ALLHAT). JAMA. 2002; 288: 2981-97.

Bots ML, Remme WJ, Luscher TF, Fox KM, Bertrand M, Ferrari R, Simoons ML, Grobbee DE. ACE inhibition and endothelial function: Main findings of PERFECT, a sub-study of the EUROPA trial. Cardiovasc Drugs Ther. 2007; 21: 269-79.

Brodszky V, Nagy V, Farsang C, Kárpáti K, Gulácsi L. The efficacy of indapamide in different cardiovascular outcome: Meta-analysis. Orv Hetil. 2007; 148: 1203-11.

Brugts JJ, Ninomiya T, Boersma E, Remme WJ, Bertrand M, Ferrari R, Fox K, MacMahon S, Chalmers J, Simoons ML. The consistency of the treatment effect of an ACE-inhibitor based treatment regimen in patients with vascular disease or high risk of vascular disease: A combined analysis of individual data of ADVANCE, EUROPA, and PROGRESS trials. Eur Heart J. 2009; 30: 1385-94.

Bulpitt CJ, Beckett NS, Peters R, Leonetti G, Gergova V, Fagard R, Burch LA, Banya W, Fletcher AE. Blood pressure control in the Hypertension in the Very Elderly Trial (HYVET). J Hum Hypertens. 2011; 2011.

Carter AB. Hypotensive therapy in stroke survivors. Lancet 1970; 1 : 485-89.

Ceconi C, Fox KM, Remme WJ, Simoons ML, Bertrand $\mathrm{M}$, Parrinello G, Kluft C, Blann A, Cokkinos D, Ferrari R; EUROPA Investigators; PERTINENT Investigators the Statistical Committee. ACE inhibition with perindopril and endothelial function: Results of a substudy of the EUROPA study: PERTINENT. Cardiovasc Res. 2007; 73: 237-46.

Chobanian AV, Bakris GL, Black HR, Cushman WC, Green LA, Izzo JL Jr, Jones DW, Materson BJ, Oparil S, Wright JT Jr, Roccella EJ. Joint National Committee on Prevention, Detection, Evaluation, and Treatment of High Blood Pressure: National High Blood Pressure Education Program Coordinating Committee. Seventh Report of the Joint National Committee on Prevention, Detection, Evaluation, and treatment of high blood pressure. Hypertension 2003; 42: $1206-52$.

de Leeuw PW. Combination perindopril/indapamide for the treatment of hypertension: A review. Expert Opin Pharmacother. 2011; 12: 1827-33.

Debbabi H, Bonnin P, Levy BI. Effects of blood pressure control with perindopril/indapamide on the microcirculation in hypertensive patients. Am J Hypertens. 2010; 23: $1136-43$.

Gosse P. Perindopril/indapamide combination in the first-line treatment of hypertension and end-organ protection. Expert Rev Cardiovasc Ther. 2006; 4: 319-33.

Ghiadoni L. Perindopril for the treatment of hypertension. Expert Opin Pharmacother. 2011; 12: 1633-42.

Ghiadoni L, Magagna A, Kardasz I, Taddei S, Salvetti A. Fixed dose combination of perindopril and indapamide improves peripheral vascular function in essential hypertensive patients. Am J Hypertens. 2009; 22: 506-12.

Gueyffier F, Froment A, Gouton M. New meta-analysis of treatment trials of hypertension: Improving the estimate of therapeutic benefit. J Hum Hypertens. 1996; 10: 1-8.

Hypertension-Stroke Cooperative Study Group. Effect of antihypertensive treatment on stroke recurrence. JAMA. 1974; 229: 409-18.

HYVET Study Group. Treatment of hypertension in patients 80 years of age or older. N Engl J Med. 2008; 358: 1887-98.

Kang S, Wu YF, An N, Ren M. A systematic review and metaanalysis of the efficacy and safety of a fixed, low-dose perindopril-indapamide combination as first-line treatment of hypertension. Clin Ther. 2004; 26: 257-70.

Kearney PM, Whelton M, Reynolds K, Muntner P, Whelton PK, He J. Global burden of hypertension: Analysis of worldwide data. Lancet 2005; 365: 217-23.

Laurent S. Very-low-dose combination of perindopril and indapamide: Efficacy on blood pressure and target-organ damage. J Hypertens Suppl. 2003; 21: S11-18.

Liu L, Wang Z, Gong L, Zhang Y, Thijs L, Staessen JA, Wang J. Blood pressure reduction for the secondary prevention of stroke: A Chinese trial and a systematic review of the literature. Hypertens Res. 2009; 32: 1032-40.

López-Sendón J, Swedberg K, McMurray J, Tamargo J, Maggioni AP, Dargie H, Tendera M, Waagstein F, Kjekshus J, Lechat P, Torp-Pedersen C; Task Force on ACE-inhibitors of the European Society of Cardiology. Expert consensus document on angiotensin converting enzyme inhibitors in cardiovascular disease: The Task Force on ACE-inhibitors of the European Society of Cardiology. Eur Heart J. 2004; 25: 1454-70.

Mancia G, Laurent S, Agabiti-Rosei E, Ambrosioni E, Burnier M, Caulfield MJ, Cifkova R, Clément D, Coca A, Dominiczak A, Erdine S, Fagard R, Farsang C, Grassi G, Haller H, Heagerty A, Kjeldsen SE, Kiowski W, Mallion JM, Manolis A, Narkiewicz K, Nilsson P, Olsen MH, Rahn KH, 
Redon J, Rodicio J, Ruilope L, Schmieder RE, StruijkerBoudier HA, van Zwieten PA, Viigimaa M, Zanchetti A; European Society of Hypertension. Reappraisal of European guidelines on hypertension management: A European Society of Hypertension Task Force document. J Hypertens. 2009; 27: 2121-58.

Mancia G, Grassi G. Protection of patients with diabetes, with or without hypertension: Implications of ADVANCE for clinical practice. J Hypertens Suppl. 2009; 27: S19-23.

McClellan KJ, Markham A. Perindopril $2 \mathrm{mg} /$ indapamide $0.625 \mathrm{mg}$. Fixed low-dose combination. Drugs. 1999; 58: 297 302.

PATS Collaborating Group. Post-stroke antihypertensive treatment study: A preliminary result. Chin Med J. 1995; 108: 710 -17 .

PROGRESS Collaborative Group. Randomised trial of a perindopril-based blood-pressure-lowering regimen among 6105 individuals with previous stroke or transient ischaemic attack. Lancet 2001; 358: 1033-41.

Psaty BM, Smith NL, Siscovick DS, Koepsell TD, Weiss NS, Heckbert SR, Lemaitre RN, Wagner EH, Furberg CD. Health outcomes associated with antihypertensive therapies used as first-line agents: A systematic review and meta-analysis. JAMA. 1997; 277: 739-45.

Rashid P, Leonardi-Bee J, Bath P. Blood pressure reduction and secondary prevention of stroke and other vascular events: A systematic review. Stroke 2003; 34; 2741-48.

Rodriguez-Granillo GA, Vos J, De Feyter PJ. Long-term effect of perindopril on coronary atherosclerosis progression (from the PERindopril's Prospective Effect on Coronary a Therosclerosis by Angiography and Intravascular Ultrasound Evaluation [PERSPECTIVE] Study). Am J Cardiol.
2007; 100: 159-63.

Rodriguez-Granillo GA, de Winter S, Bruining N, Ligthart JM, García-García HM, Valgimigli M, de Feyter PJ; EUROPA/ PERSPECTIVE Investigators. Effect of perindopril on coronary remodelling: Insights from a multicentre, randomized study. Eur Heart J. 2007; 28: 2326-31.

Snyman JR, Wessels F. Perindopril: Do randomised, controlled trials support an ACE inhibitor class effect? A meta-analysis of clinical trials. Cardiovasc J Afr. 2009; 20: 127-34.

Stamler J, Stamler R, Neaton JD. Blood pressure, systolic and diastolic, and cardiovascular risks: U.S. population data. Arch Intern Med. 1993; 153: 598-615.

SHEP Cooperative Research Group. Prevention of stroke by antihypertensive drug treatment in older persons with isolated systolic hypertension. Final results of the Systolic Hypertension in the Elderly Program (SHEP). JAMA. 1991; 265: 3255-64.

The Task Force on the Management of Stable Angina Pectoris of the European Society of Cardiology. Guidelines on the management of stable angina pectoris. Eur Heart J. 2006; 27: 1341-81.

The Task Force for the Management of Arterial Hypertension of the European Society of Hypertension (ESH) and of the European Society of Cardiology (ESC). 2007 Guidelines for the management of arterial hypertension. J Hypertens. 2007; 25: $1105-87$.

Wood D, DeBacker G, Faergeman O, Graham I, Mancia G, Pyorala K, and the task force. Prevention of coronary heart disease in clinical practice: Recommendation of the second Joint Task Force of European and other societies on Coronary Prevention. Atherosclerosis 1998; 140: 199-270. 